\title{
Diabetes Education: the Experiences of Young Adults with Type 1 Diabetes
}

\author{
Janice Wiley $\cdot$ Mary Westbrook $\cdot$ Janet Long $\cdot$ \\ Jerry R. Greenfield $\cdot$ Richard O. Day \\ Jeffrey Braithwaite
}

To view enhanced content go to www.diabetestherapy-open.com

Received: November 18, 2013 / Published online: February 12, 2014

(c) The Author(s) 2014. This article is published with open access at Springerlink.com

\section{ABSTRACT}

Introduction: Clinician-led diabetes education is a fundamental component of care to assist people with Type 1 diabetes (T1D) self-manage their disease. Recent initiatives to incorporate a more patient-centered approach to diabetes education have included recommendations to make such education more individualized. Yet there is a dearth of research that identifies patients' perceptions of clinician-led diabetes

Electronic supplementary material The online version of this article (doi:10.1007/s13300-014-0056-0) contains supplementary material, which is available to authorized users.

J. Wiley $(\bowtie) \cdot$ M. Westbrook $\cdot$ J. Long ·

J. Braithwaite

Centre for Clinical Governance Research in Health, Australian Institute of Health Innovation, University of New South Wales, Sydney, Australia

e-mail: j.wiley@unsw.edu.au

J. R. Greenfield

Garvan Institute of Medical Research, Sydney,

NSW, Australia

R. O. Day

Department of Clinical Pharmacology, St Vincent's Hospital, University of New South Wales, Sydney, Australia education. We aimed to describe the experience of diabetes education from the perspective of young adults with T1D.

Methods: We designed a self-reported survey for Australian adults, aged 18-35 years, with T1D. Participants $(n=150)$ were recruited by advertisements through diabetes consumerorganizations. Respondents were asked to rate aspects of clinician-led diabetes education and identify sources of self-education. To expand on the results of the survey we interviewed 33 respondents in focus groups.

Results: Survey: The majority of respondents (56.0\%) were satisfied with the amount of continuing clinician-led diabetes education; $96.7 \%$ sought further self-education; $73.3 \%$ sourced more diabetes education themselves than that provided by their clinicians; $80.7 \%$ referred to diabetes organization websites for further education; and 30.0\% used online chatrooms and blogs for education. Focus groups: The three key themes that emerged from the interview data were deficiencies related to the pedagogy of diabetes education; knowledge deficiencies arising from the gap between theoretical diabetes education and practical reality; and the need for and problems 
associated with autonomous and peer-led diabetes education.

Conclusion: Our findings indicate that there are opportunities to improve clinician led-diabetes education to improve patient outcomes by enhancing autonomous health-literacy skills and to incorporate peer-led diabetes education and support with clinician-led education. The results provide evidence for the potential value of patient engagement in quality improvement and health-service redesign.

Keywords: Diabetes education; Endocrinology; Patient-centered care; Patient education; Patient perspective; Qualitative research; Type 1 diabetes; Young adults

\section{INTRODUCTION}

Type 1 diabetes (T1D) is an autoimmune disease that necessitates lifelong insulin replacement therapy. Effective self-management of T1D has evolved to require patients to have an ability to formulate algorithms for insulin replacement dependent upon a complex array of interactive physiological parameters [1]. These parameters include consideration for dietary carbohydrate content and metabolism [2-5], personal glycemic patterns $[6,7]$, and adjustment for situations such as exercise or sick days [8]. Although tight glycemic control has been shown to delay or prevent the onset of diabetes-related micro-vascular and macrovascular complications [9-12], the complexity of self-management has meant that the majority of people with T1D fail to maintain recommended levels of glycemic control [13-15]. Thus, the long-term prognosis for a person with T1D remains poor [16].

Diabetes education is a complex clinical intervention that provides the person with the knowledge and skills needed to perform diabetes self-care and make lifestyle changes to successfully manage the disease $[17,18]$. As it has been estimated that $95 \%$ of diabetes care is self-management [19], clinician-led diabetes education is a fundamental component of assistance for people with T1D [20]. Clinical guidelines for the management of T1D recommend that diabetes education be provided to the patient by the diabetes health care team at diagnosis and at regular intervals throughout the patient journey [21-23]. Traditionally clinicians, who may include endocrinologists, diabetes educators (accredited diabetes nurse specialists), dietitians, or general practitioners (GP), have delivered diabetes education in a one-on-one situation with the patient. Evidence suggests that such education may be unstructured and provide inadequate knowledge to promote effective self-management [24]. National diabetes educator accreditation has been implemented in many countries to maintain higher standards of diabetes education [25-29]. However, there remains limited understanding of factors that may act as barriers or enablers to effective self-management knowledge translation [18, 30].

As health systems move toward more patient-centered systems of care, the pedagogy of diabetes education has developed to emphasize patient autonomy and consideration for patient lifestyle preferences [31, 32]. Research has supported this transformation [33-35]. A recent development has been the move to conduct structured group diabetes education courses $[1,18]$. A theoretical basis in Social Learning Theory, which emphasizes skills attainment through observation, imitation, and modeling, has driven this development [36]. One internationally prominent course is the Dose 
Adjustment for Normal Eating (DAFNE) program [37] available in the United Kingdom, Ireland, Australia, Singapore, and Kuwait [1, 13, 37, 38]. The course evolved from the German Structured Teaching and Treatment Programme [39]. Within those countries that have adopted the DAFNE course there are no published data available that quantify the uptake of the program by suitable participants. It is now suggested that graduates of the DAFNE course would benefit from individualized follow up from suitably trained clinicians on an 'as needs' basis [40]. Such follow-up recommendations coincide with the American Diabetes Educators Association position statement call for diabetes education to be more 'individualized' [41].

In order to implement diabetes education that is tailored to the individual, clinicians need to identify issues that people with T1D perceive as enablers or barriers for effective diabetes education. Yet there are few studies that seek to understand, from the patient's perspective, the factors that impact on this process. Whilst the DAFNE group has undertaken qualitative research with the graduates of that course [42], there are no peer-reviewed published data on the perspectives of adults with T1D that have not undertaken specific structured education programs. This study seeks to address the research gap.

Young adults with T1D are of particular interest as they are recognized as being more technologically experienced [43, 44], but have high attrition rates from diabetes health services $[45,46]$ and suffer worse health outcomes [45]. In order to attract young adults to take up recommended health services, there is a strong imperative to make those services more patientcentered; that is that the services meet the patients' needs and preferences. This study aims to identify the aspects of diabetes education that young adults consider could be more comprehensively addressed, thereby enhancing their autonomy and confidence in diabetes self-management. We set out to determine young adult's perceptions and experiences of clinician-led diabetes education and to identify other ways in which they gained knowledge to manage their diabetes.

\section{METHODS}

\section{Study Population}

The study population was a sample of Australian adults, aged 18-35 years, with T1D. Participants were recruited in 2011 from Australian diabetes consumer support organizations via advertisements on websites, e-newsletters, Facebook, and print journals. To obtain qualitative data, focus groups were conducted in all state capital cities excepting Hobart with some participants traveling from regional areas. Focus groups were not conducted in Hobart due to the low response rate, which reflects the population size of the smallest state capital in Australia. Age-limited inclusion criteria for the study were established for the reasons previously described [43-46]. Exclusion criteria were people with T1D outside of the set age limits, people with T1D not living in Australia, and carers of those with T1D.

The University of New South Wales granted ethics approval: HREC 10395.

All procedures followed were in accordance with the ethical standards of the responsible committee on human experimentation (institutional and national) and with the Helsinki Declaration of 1975, as revised in 2000 and 2008. Informed consent was obtained from all patients for being included in the study. 


\section{Study Design}

The study design involved a mixed methods approach to survey and sought the perspectives of a defined population.

\section{Survey}

The quantitative component of the study consisted of a web-based, self-reported, crosssectional survey of methods of diabetes selfmanagement. The survey was available online from February to May 2011. A paper version of the survey was available but not utilized by any respondent. The survey consisted of 96 questions that covered a comprehensive assessment of factors relevant to T1D selfmanagement although not all questions were relevant to every respondent. For example, questions related to the use of continuous insulin infusion devices were not relevant to respondents who used multiple daily injections. The survey was piloted on a sample of four young adults with T1D and ten health-services workers and researchers. Recommended improvements were incorporated into the final version of the survey.

Following assessment of respondent demographic characteristics, the survey addressed questions related to mode, frequency, and evaluation of insulin delivery and blood glucose monitoring systems. The survey also explored respondents' record keeping, dietary management; insulin adjustment and the use of blood glucose target levels (including for exercise, sick days, and alcohol consumption), identification and evaluation of health services, and diabetes education accessed.

Participants were asked to nominate from whom they received their initial diabetes education. They were asked to rate, using a seven point Likert scale, whether they had been adequately educated on nominated aspects of diabetes self-management, whether they were confident to manage those aspects of their diabetes care, and whether they sourced more diabetes education themselves than their health team provided. Participants were asked to nominate the sources that they referred to for further diabetes education.

\section{Focus Groups}

To expand on the results of the survey, participants were invited by email to attend focus groups. This method was chosen as focus groups can promote participants' interactions in ways that may not come to light in personal interviews [47]. Focus groups were conducted from May to August 2011. Sixty-eight respondents expressed interest in attending the focus groups, but only 33 were available for the organized dates and venues. Six focus groups were conducted with a range of three to seven participants.

One researcher (JW) conducted all focus groups using a semi-structured format of openended questions. The open-ended questions allowed for the exploration of the participants' experiences of diabetes education beyond those considered in the survey questions. Focus group discussion continued until content saturation was achieved. Focus groups were electronically recorded and transcribed verbatim. The researcher wrote notes after each meeting, reflecting on the principal matters discussed and recording the perceived feelings, emotions, and personal interactions of the participants.

\section{Data Processing and Analysis}

Of 167 commenced survey responses, 150 respondents completed all relevant survey 
questions. Only completed responses were incorporated into the data analyses. For the purpose of reporting questions that were rated on the seven-point Likert scale, the three levels of agreement and of disagreement were combined, with the neutral score remaining constant. Quantitative analysis was undertaken using SPSS $^{\circledR}$ (Version 20.0, SPSS Inc., Chicago, USA). Sections of the survey also provided for free text responses. These responses were incorporated with the qualitative data generated by the focus groups.

Qualitative data analysis was broadly interpretative, as we wanted to focus on health system applications, in areas identified by the focus group attendees that would improve the quality of diabetes education. To do this, we drew on the inductive analytic approach of interpretive description [48] whose tradition is based on seeking opportunity for real world applications for health service improvement. Two health services researchers, a registered nurse (JL), and a registered medical practitioner (JW) with clinical experience in diabetes care independently analyzed the data. Data were coded into recurring themes and sub-themes related to participants' experiences of diabetes education with the aid of qualitative research software, QRS NVivo (Version 9.0, QSR International Pty Ltd, Australia). A third health services researcher (MW) analyzed the quantitative and qualitative data to check for thematic consistency and interpretative analysis.

Qualitative studies such as this one collect large amounts of data from a small number of informants or study sites. They are not designed to estimate proportions in a wider population, quantify relationships between pre-determined variables, or provide a single representative or average view or opinion. Instead, they seek to document and explain the variation in a wide range of views, needs, values, practices, and beliefs.

\section{RESULTS}

\section{Survey Results}

\section{Demographic Characteristics of the Survey Respondents}

The sample participants had the following characteristics: $30.5 \%$ were aged $18-24$ years, $34.4 \%$ were $25-29$ years and $35.1 \%$ were 30-35 years; $79.5 \%$ of respondents were females; $80.0 \%$ came from eastern seaboard states (reflecting Australian population demographics); $68.0 \%$ were living in major cities; $79.0 \%$ had attained an education level of tertiary or higher, $64.0 \%$ were working full time, $10.0 \%$ were working part time, $13.0 \%$ were studying, 5.0\% were not employed, and $8.0 \%$ combined a variety of roles, and $84.0 \%$ had private health insurance.

\section{Diabetes Characteristics of the Survey Respondents}

Clinical diabetes characteristics were selfreported and are listed in Table 1 . Ten percent of respondents owned continuous glucose monitoring (CGM) devices and 18.5\% had CGM preformed intermittently. To deliver insulin, $40.4 \%$ of respondents used a continuous insulin infusion device. Of the 90 respondents who used a subcutaneous insulin injection method, $5.6 \%$ had 1-3 daily injections, $57.3 \%$ had 4 daily injections, and $37.1 \%$ had more than 4 injections per day.

\section{Consultation Characteristics of the Survey Respondents}

The numbers of respondents who currently consulted with recommended clinicians were 
Table 1 The clinical characteristics of survey participants $(n=150)$

Duration of diabetes in years

$\begin{array}{lc}<5 & 38(25.3 \%) \\ 5-10 & 30(20.0 \%) \\ 11-15 & 23(15.3 \%) \\ 16-20 & 26(17.3 \%) \\ >20 & 33(22.0 \%) \\ \text { Last HbAlc } & \\ \text { Don't know } & 6(4.0 \%) \\ <7 \% & 51(34.0 \%) \\ 7.1-7.5 \% & 30(20.0 \%) \\ 7.6-8 \% & 18(12.0 \%) \\ 8.1-8.5 \% & 21(14.0 \%) \\ 8.6-9 \% & 9(6.0 \%) \\ >9 \% & 15(10.0 \%)\end{array}$

$\mathrm{HbA}$ and $\mathrm{HbAlc}$ performed in the past 6 months

\begin{tabular}{lc} 
Yes & $135(90.0 \%)$ \\
No & $15(10.0 \%)$ \\
BMI & \\
Don't know & $34(22.7 \%)$ \\
$<19$ & $5(3.3 \%)$ \\
$19-24$ & $67(44.7 \%)$ \\
$25-30$ & $33(22.0 \%)$ \\
$>30$ & $11(7.3 \%)$ \\
\hline
\end{tabular}

$B M I$ body mass index, $H b A$ glycated hemoglobin $\mathrm{A}$, HbAlc glycated hemoglobin Alc

endocrinologists, $135 \quad(90.0 \%) ; \quad$ diabetes educators, 89 (59.3\%); dieticians, 50 (33.3\%); psychologist/psychiatrist/social worker 34 (22.7\%); and GPs, 56 (37.3\%). Four respondents $(2.7 \%)$ did not currently consult any clinician. The average number of clinicians that respondents consulted to assist with selfmanagement was 2.3 .

\section{Diabetes Education Characteristics}

\section{of the Sample}

At initial diabetes diagnosis 112 (74.7\%) of all respondents or their family members received diabetes education from an endocrinologist or specialist physician, 116 (77.3\%) from a diabetes educator, 87 (58.0\%) from a dietician, and $40(26.7 \%)$ from a GP. Due to age at diagnosis, three (2\%) respondents were not aware of whether any initial diabetes education was provided.

Fifty-six percent of respondents were satisfied with the amount of continuing diabetes education that they received from their health care team, $76.6 \%$ were confident about how to calculate bolus insulin requirements for meals, $64.0 \%$ were confident about how to calculate basal insulin requirements, $66.0 \%$ agreed that it had been adequately explained to them how to manage their diabetes when sick, $66.7 \%$ agreed that it had been adequately explained to them how to manage their diabetes when exercising, and $76.7 \%$ agreed that the effect that alcohol had on their diabetes had been adequately explained to them. Respondent results for complete Likert scale ratings for questions related to diabetes education are listed in Table 2.

To estimate insulin requirements for food consumption, respondents used a variety of methods concurrently: 122 (81.3\%) counted carbohydrate content, 38 (25.3\%) used an exchange method, 28 (18.7\%) considered the glycemic index of the food, and 97 (64.7\%) generally used past experience for how much insulin to administer. Sixty-eight respondents (45.3\%) stated that they had been educated on the recommended daily requirements of different food groups while 81 (54\%) had been educated about the use of glycemic index.

One hundred and forty-five (96.6\%) of the respondents' accessed further diabetes 





Table 3 The additional organizational, media and print diabetes education resources used by survey respondents $(n=150)$

\begin{tabular}{lc}
\hline Resource & Result \\
\hline Diabetes support organization websites & $121(80.7 \%)$ \\
Diabetes support organization magazines & $99(66.0 \%)$ \\
Books & $68(45.3 \%)$ \\
Medical technology company websites & $64(42.7 \%)$ \\
Diabetes support organization chat-rooms/ & $45(30 \%)$ \\
blogs & $44(29.3 \%)$ \\
Other websites & $30(20.0 \%)$ \\
Diabetes support organization seminars & $5(3.3 \%)$ \\
\hline I do not access further education & \\
\hline
\end{tabular}

education resources themselves and 110 $(73.3 \%)$ of respondents stated that they sourced more diabetes information themselves than the overall amount of information that was provided by their health care team diabetes education. The diabetes education resource that respondents referred to the most was diabetes support organization websites at $80.7 \%$. The self-education resources that our respondents utilized are listed in Table 3.

\section{Focus Groups}

\section{Characteristics of Focus Group Participants}

These were a sub-set of the Survey participants. Twenty-seven females (81.8\%) and six males $(18.1 \%)$ attended the focus groups. All participants came from major or regional cities. Their mean age was 25.1 years with a range from 20 to 33 years. The mean duration of T1D was 10.5 years with a range of duration from 0.5 to 25 years. Seven participants $(21.2 \%)$ used continuous insulin infusion devices. One participant (3.0\%) had previously used such a device but had reverted to multiple daily injections. Two participants (6.1\%) identified as [TOB: female age 31, T1D mellitus (T1D) duration 20 years] and [SAB: female age 24 , T1D duration 18 years] had attended the Dose Adjustment for Normal Eating (DAFNE) course. One participant identified as [HEP: female age 28, T1D duration 2 years] had attended another type of structured reeducation program when she was previously a resident in the United Kingdom.

\section{Focus Group Results}

Following thematic analysis of the qualitative data, three key themes emerged that reflected the commonly shared experiences of many participants. These themes were summarized as follows: deficiencies in the pedagogy of diabetes education; knowledge deficiencies arising from the gap between theoretical diabetes education and practical reality; and the problems associated with autonomous and peer-led diabetes education and the need for more such education. Table 4 shows the hierarchy of the themes and sub-themes identified in the thematic analysis.

\section{Deficiencies in the Pedagogy of Diabetes Education}

Participants reported that there were deficiencies related to the pedagogy of diabetes education. The reported deficiencies varied by the age of the participant at diabetes diagnosis and reflected their initial experience of diabetes education. Reported deficiencies also related to the teaching methods employed by clinicians. A lack of utilization of problem-based learning and failure to encourage autonomous learning were reported. Reliance by clinicians on piecemeal diabetes educational updates rather than provision of a comprehensive re-education program was perceived by participants as a 
Table 4 Thematic analysis of focus group results

\begin{tabular}{|c|c|c|}
\hline $\begin{array}{l}\text { Corresponding } \\
\text { table }\end{array}$ & Overarching theme & Subtheme \\
\hline \multirow[t]{6}{*}{5} & $\begin{array}{l}\text { Deficiencies in the pedagogy of } \\
\text { diabetes education }\end{array}$ & Impact of age at initial diabetes education \\
\hline & & $\begin{array}{l}\text { Diabetes knowledge deficiencies not identified in continuing } \\
\text { education }\end{array}$ \\
\hline & & $\begin{array}{l}\text { Failure of clinicians to refer to comprehensive structured } \\
\text { education programs }\end{array}$ \\
\hline & & Pedagogy did not promote autonomous learning \\
\hline & & Variation in personal motivation towards education \\
\hline & & Failure of clinicians to refer to new technologies \\
\hline \multirow[t]{3}{*}{6} & $\begin{array}{l}\text { The gap between theoretical } \\
\text { diabetes self-management } \\
\text { education and practical reality }\end{array}$ & Unpredictable variation in glycemic response \\
\hline & & The provision of conflicting advice by clinicians \\
\hline & & The impact of inflexible self-management regimen education \\
\hline \multirow[t]{3}{*}{7} & $\begin{array}{l}\text { Peer-led and autonomous diabetes } \\
\text { education }\end{array}$ & The value of peer-led learning \\
\hline & & Taboo subjects in clinician-led education \\
\hline & & Diabetes consumer organization-led learning \\
\hline
\end{tabular}

cause in the development of knowledge gaps in the understanding of diabetes management. Participants identified contextual factors that promoted diabetes learning. Participants reported the failure by some clinicians to promote independent established structured diabetes education programs and information about new technologies that assisted selfmanagement. Relevant participant quotations for these subthemes are reported in Table 5.

Impact of Age at Initial Diabetes Education Participants' experiences of their initial diabetes education differed dependent upon their age at diabetes diagnosis. Two distinct group experiences emerged: those whose parents had primarily been educated by clinicians due to the patient's young age at diagnosis and those who had been the primary recipient of clinician-led education. Participants, whose diabetes was diagnosed at an age when their parents were responsible for their diabetes management, reported that the majority of diabetes education had been directed towards their parents rather than them. This became problematic for the participant at an age when they were required to become autonomous for their diabetes management, as the initial intensive clinicianled diabetes education provided to the parent was never repeated for the participant (Quotation 1). 
Table 5 Respondent quotations related to deficiencies in the pedagogy of diabetes education

\section{Quote Quotation \\ number}

1.1 Impact of age at initial diabetes education

1 "I was seven when I was diagnosed. My parents were educated, not me. This has been problematic as I feel as though I was never properly educated." [DOS: female, age 32, T1DM duration 25 years]

2

"When I was first diagnosed they told my parents what could happen ... They didn't tell me. It was mainly a parent sort of thing

Whereas, all of a sudden, I was then supposed to know about it! I was too young to take it in initially and they didn't tell me again

... They just assume that you know it when you are 18 or 19." [TOB: female, age 31, T1D duration 20 years]

3

"I never got educated ... my parents were the ones that were educated." [SUM: female, age 31, T1D duration 21 years]

4

"I was overwhelmed with the information that they gave me: now I'm not even sure what the complications are." [DAS: female, age 32, T1D duration 2 years]

\subsection{Diabetes knowledge deficiencies not identified in continuing education}

"My knowledge is probably really archaic because it has never been updated. It is just what I have gathered. ... It's probably not the best knowledge at all but it's just sort of been gathered knowledge." [SUM: female, age 31, T1D duration 21 years]

6 'I was (adjusting insulin) off instinct. No it's like guesswork. ... I'd never actually been educated. My parents were educated when I was six years old and I mean my parents are busy and I like literally just used guesswork over the years. So I've only really had DAFNE.” [SAB: female, age 24, T1D duration 18 years]

\subsection{Failure of clinicians to refer to structured education programs}

7 'I don't know anything about DAFNE. Because I've been handling it fine he (the endocrinologist) doesn't offer anything.” [NIB: female, age 26, T1D duration 2 years]

\subsection{Pedagogy did not promote autonomous learning}

8 "Maybe if I was encouraged when I was younger to look for the information or if the resources were given to me or made available, then I would have learnt a lot more from a younger age. ... The emphasis on giving the skills to be more autonomous ... I don't think that has been good.” [AMS: female, age 23, T1D duration 11 years]

9 “Being educated on how to educate yourself would be a lifesaver." [RAS: female, age 30, T1D duration 12 years]

1.5 Variation in personal motivation towards education

10 "Since I've graduated from high school ... all of a sudden I have grown up a lot more and I'm a lot more interested and a lot more responsible." [SAB: female, age 24, T1D duration 18 years]

1.6 Failure of clinicians to refer to new technologies

11 "I find that doctors don't know much about pumps. So they don't want to put someone on one because they are not going to be able to help them. ... Both times (for Continuous Glucose Monitoring also) I went to the endocrinologist and said 'I want to do this.' [MOM: female, age 33, T1D duration 13 years]

DAFNE Dose Adjustment for Normal Eating; TID type 1 diabetes 
Participants, whose parents were the primary recipients of clinician-led education, reported that there was an underlying assumption by clinicians that they would have acquired the diabetes knowledge imparted to their parents (Quotation 2).

However, in many instances the parent had not imparted comprehensive diabetes knowledge to their child. Although participants were provided with intermittent or piecemeal clinician-led diabetes education, they were not provided with a comprehensive diabetes education. This led to gaps in participants' knowledge. So large were these knowledge gaps that some participants expressed that they felt they had never been educated (Quotation 3).

Alternately participants, diagnosed at an age when they were the primary recipients of the clinician-led diabetes education, reported that the intensive nature of the initial diabetes education sessions, which occurred at the time when they were dealing with the psychological impact of their recent diagnosis, left them feeling overwhelmed. The timing of the comprehensive education was not conducive to knowledge retention and not repeated at a later stage (Quotation 4).

\section{Diabetes Knowledge Deficiencies Not Identified} in Continuing Education Participants commented that clinician-led continuing education tended to be piecemeal without consideration being given to possible gaps in attendees' overall knowledge. For most participants, even those diagnosed in their adolescence or adulthood, a comprehensive reeducation program had never been offered. This left many participants feeling that their education was deficient overall (Quotation 5). The two participants who had completed the DAFNE course expressed that part of the value of the course lay in the fact that it was their first exposure to a comprehensive structured education program since their initial diagnosis or ever (Quotation 6).

Failure of Clinicians to Refer to Comprehensive Structured Education Programs For a number of participants, the focus group interaction provided them, for the first time, with knowledge about the DAFNE course. Some participants perceived that there was not sufficient impetus on the part of clinicians to be proactive in directing their patients to ancillary education programs. Some participants reported clinician-based inertia toward encouragement for ancillary diabetes education. Participants reported that they believed that maintenance of an acceptable level of glycemic control heightened such clinical inertia (Quotation 7).

\section{Pedagogy Did Not Promote Autonomous}

Learning Participants reported that diabetes education tended to be structurally didactic and did not provide for the development of skills for autonomous diabetes learning. Participants expressed the need for skills that focused on problem-based learning and that encouraged autonomous learning to be incorporated into diabetes education programs (Quotations 8 and 9).

Variation in Personal Motivation Toward Education Participants reported that their interest in and retention of diabetes education had varied over the duration of their diabetes. Interest toward diabetes education was affected by contextual factors. Some participants reported that the onset of diabetes complications created an impetus to seek further education whilst others reported that the transition stage from adolescence to young 
adulthood, with the concomitant requirement for self-management autonomy, created a driver for further diabetes education (Quotation 10).

Failure of Clinicians to Refer to New
Technologies Many experienced clinician-based inertia in relation to the education around new technological advances. Participants reported that clinicians appeared to make a decision to educate patients about new technologies dependent upon whether the clinician intended to recommend those technologies in the management regimen rather than for patients' broader education. This was problematic as many participants reported that clinicians were 'technophobic' and, therefore, education related to the use of new technologies was patient instigated (Quotation 11).

The Gap Between Theoretical Diabetes SelfManagement Education and Practical Reality Participants reported a noticeable disjuncture between their theoretical education regarding diabetes self-management: the 'textbook stuff', and the practical reality of implementing that theoretical knowledge. This disjuncture was most obvious when participants believed that they had implemented treatment regimens as agreed with clinicians, but the anticipated glycemic outcomes had not occurred. Participants questioned whether diabetes physiology was sufficiently understood such that clinicians' could anticipate predicted responses. They reported that it would be helpful for clinicians to acknowledge gaps in scientific understanding. Participants reported that they frequently encountered variable glycemic responses in relation to mixed food meals and exercise. The experienced variation in glycemic response to treatment regimens acted as a basis for the provision of inconsistent advice from multi-disciplinary clinicians. The provision of inconsistent advice was a commonly reported feature that affected participants continuing diabetes knowledge translation. Some participants were able to adapt to the provision of inconsistent advice and use it to their own advantage while for others it acted as a driver away from health service utilization. Participants reported that the disjuncture occurred most obviously when knowledge translation did not provide for flexibility to make real-world patient choices. Relevant participant quotations for these subthemes are reported in Table 6.

Unpredictable Variation in Glycemic Response Many participants, particularly those with diabetes of long standing duration, reported that the disjuncture between theoretical education and the lived experience of glycemic control created a source of constant frustration. Participants reported that although they may have followed the theoretical implementation of a treatment regimen, the anticipated response was not as they had been advised would occur and might vary for any given day even when the apparent theoretical variables remained constant (Quotation 12).

Participants' experience of the disjuncture between the theoretical education and the practical reality of self-management was so commonplace that there was an underlying acceptance that there were deficiencies in the scientific understanding of diabetes (Quotation 13).

However, many participants considered that there was a need for those that provided diabetes education to acknowledge that this disjuncture between theory and the lived experience existed and that the anticipated theoretical response to a regimen may not 
Table 6 Respondent quotations related to the gap between theoretical diabetes self-management education and the practical reality

\begin{tabular}{ll}
\hline $\begin{array}{l}\text { Quote } \\
\text { number }\end{array}$ & Quotation \\
\hline
\end{tabular}

2.1 Unpredictable variation in glycemic response

12 "That is the really frustrating thing about diabetes. I find that everyone is so different and even within yourself you vary.” [NIM: male age 25 T1D duration 6 years]

13 "It is hard because there are no rules and stuff. Which makes it hard for doctors." [CHS: male, age 32, T1D duration 9 years]

14 "It's a complicated thing. That needs to be the message to be put out there. ... It would be very helpful if people could get that." [DOS: female, age 32, T1D duration 25 years]

15 "All my dietary information has come from me personally researching the information. No medical professional has helped me in this regard. Even JDRF has limited resources in this area." [MAS: female, age 23, T1D duration 13 years]

16 "Working out regimens for exercise is something I do in my spare time." [DAP: female, age 24, T1D duration 5 years]

17 "No matter what they tell you they can never know. Like even I don't know when I've had it for years now. It is always different, always different, never the same.” [CAP: female, age 21, T1D duration 17 years]

\subsection{The provision of conflicting advice by clinicians}

18 "Yeah I definitely get mixed messages. She thinks this and he thinks that and I take them all in and go "Well what do I think and what would work for me? And I trial and error them all." [MAP: female, age 24, T1D duration 2 years]

19 "It is better that they tell you a heap of stuff and you just listen to what you want to and then adapt it for you. I've had about 50 different doctors and I know what works for me and if they try and tell me stuff I just say 'Yes' but then I don't do it because I know how I work and I know how to do it better than they do.” [CAP: female, age 21, T1D duration 17 years]

"It is really hard because I don't know who to listen to. There is me, and what I want. But then I feel I should be doing what the doctor tells you to do. But then I go, 'Hang on, they don't actually know what they are taking about!' [HEP: female, age 28, T1D duration 2 years]

"I don't even tend to ask them anymore. I either do it myself or look it up online." [RAP: female, age 25, T1D duration 3 years]

\subsection{The impact of inflexible self-management regimen education}

22 "It is really difficult when the dietician says you must eat this or that. In the real world on any given day you may or may not be able to make choices so although there is a best-case scenario that you should follow, the reality is that you can't. You can only make the best possible choices in any situation. I don't think that type of information can be translated or given to someone." [DAP: male, age 24, T1D duration 5 years]

JDRF Juvenile Diabetes research Foundation, TID type 1 diabetes 
occur for reasons that are not fully understood (Quotation 14).

There were two issues that participants commonly reported as giving rise to inconsistencies between the educational theory of self-management and their lived experience. These were dealing with diet, in particular mixed food meals, and exercise. Participants found that clinician-led dietary education that addressed the practical reality of a glycemic response to mixed food meals was inadequate and that information on this topic was difficult to access (Quotation 15).

The ability to access quality information on how to maintain glycemic control whilst exercising was a source of frustration for many participants. One participant had established an Australia-wide support group specifically to deal with this problem. Many participants had ceased relying on educational theories and resorted to trial and error (Quotations 16 and 17).

The Provision of Conflicting Advice by Clinicians Participants reported that the disjuncture between theoretical education and the practical reality of self-management implementation gave rise to the provision of inconsistent advice from and between the clinicians that they consulted. This also led participants to adopt a trial and error approach to self-management (Quotation 18).

For some participants the repeated inconsistencies in theoretical knowledge provided by clinicians and their need to resort to a "trial and error" approach led them to consider that their own health literacy, gained from the lived experience, was more beneficial than that offered by the clinicians (Quotation 19). But for other participants this knowledge disjuncture and the inconsistent advice of clinicians left them in a state of confusion about how they should manage their disease (Quotation 20). For other participants the repeated inconsistencies in advice had acted as a driver for them to stop utilizing health services (Quotation 21).

\section{The Impact of Inflexible Self-Management} Regimen Education The disjuncture was heightened when diabetes education, based on best practice models, was not aligned with everyday choices, or provided for realistic flexibility (Quotation 22).

\section{Peer-led and Autonomous Diabetes Education}

Participants held that peer-led knowledge translation was an integral component of diabetes education. Many participants reported that peer-led learning provided opportunity for real-life explanations or solutions to self-management problems often not provided for in clinician-led education. Other participants were wary of the credibility of information gained through peers. Participants reported that for some selfmanagement issues, such as those related to sexual function and recreational drug use, peerled or autonomous learning provided the only source of information available. Participants reported that diabetes consumer organizations were a viable source of education and that technology had the capacity to improve access to education but that clinicians and diabetes consumer organizations underutilized technology as a teaching tool. Relevant participant quotations for these subthemes are reported in Table 7 .

The Value of Peer-led Learning Participants expressed the view that, as formal diabetes education did not elaborate on the disjuncture between the theoretical glycemic response and the practical reality, peer-led education had 
Table 7 Respondent quotations related to peer-based and autonomous diabetes education

\begin{tabular}{ll}
\hline Quote & Quotation \\
number &
\end{tabular}

3.1 The value of peer-based learning

23 "I learn things from other people with diabetes all the time. All the time." [MOM: female, age 33, T1D duration 13 years]

24 'It's comforting to realize that other people are going through the same thing that you are, which you don't get through a doctor. The doctor never says 'I have another patient going through a similar experience'. But that's a help!" [RAS: female, age 30, T1D duration 12 years]

"I found other diabetics have been the easiest people to talk to cause you hear some things from the medical professions where I have just gone 'Nuh! Surely there is a way around that one'. And having other diabetics around has helped amazingly." [DOS: female, age 32, T1D duration 25 years]

"Stress impacts on my BSL but I was never warned that it
system." [SAB: female, age 24, T1D duration 18 years]

27 "(Name of chat room): Every so often if I have a question and I want some advice then I will look it up. For example, when I went traveling by myself I looked it up and saw what everyone else had given about what to carry on the plane: all sorts of different bits and pieces. It is good to be able to find information from other people who are living with diabetes and have had similar experiences as well.” [RAP: female, age 20, T1D duration 3 years]

"(In diabetes education) there is still very much this didactic direction of 'this is what you can and can't do'. I find people with diabetes act that way as well. So participating in a chat room? No thanks I'd rather just go my own way." [AMM: female, age 33, T1D duration 25 years]

"No I'd be a bit skeptical going on to diabetes forums because you don't know if the information is genuine." [KRS: female, age 33, T1D duration 6 years]

\subsection{Taboo subjects in clinician led education}

30 "I have had diabetes for 20 years... You gradually work out what works for you. For example when I'm menstruating I have to drop my long acting insulin. Things like that I had to work out for myself. I wasn't ever educated on how menstruation impacts on your BSLs”. [AMM: female, age 33, T1D duration 25 years]

"I have a friend and we talk between us: like after alcohol I always crash and I can eat five times as much without doing insulin. I talk to her about that stuff and she says 'Yeah I'm like that'. So we see what is normal by comparing what happens to us.” [MAP: female, age 24, T1D duration 2 years]

"I took party drugs in my twenties and the only way I knew how to manage my diabetes was by asking other people with diabetes. My diabetic friends figured out what sort of effect that it would have on our blood sugars and so I would have a basic idea about how to manage at a party that way." [DOS: female, age 32, T1DM duration 25 years]

\subsection{Diabetes consumer organization led learning}

"I've taken days off work to attend these meetings but you can't keep doing that." [RAS: female, age 30, T1DM duration 12 years]

34 "I get invites (from diabetes support organizations) about sessions that I think would be useful for me to attend but they are run at a time that I can never attend. Maybe the flexibility needed isn't to run them at another time but to make them available via technology. The session doesn't have to change schedule but just let me access it." [CHS: male, age 32, T1DM duration 9 years] duration 12 years]

BSLs blood sugar levels, TID type 1 diabetes 
become an important component in improving their health literacy (Quotation 23).

The ways in which participants had established peer-networks to improve health literacy varied. These included the following: having friends or relatives with diabetes; meeting other people with diabetes at hospital-based clinics or diabetes support organization functions; establishing specialized-function support groups in particular related to exercise; and establishing Facebook groups and online chat-rooms. Peerled discussion not only provided a basis for education but also for reassurance that it was common that the lived experience of effective diabetes self-management differed from theoretically based education scenarios; a factor that participants found was not emphasized in clinician-led education (Quotation 24).

Peer-led education provided solutions for self-management issues that were not sufficiently covered by clinician-led education (Quotation 25).

There were day-to-day issues that a number of participants reported that clinician-led education had not considered. These included dealing with the glycemic response in relation to stress or mental challenges in work or study (Quotation 26).

Of participants who were aware of or had used chat-rooms for diabetes self-management, there was divergence in opinion as to their value as an educational tool. Some participants supported the educational role of such sites (Quotation 27); others found that the pedagogy of chat-room learning was not suitable for them (Quotation 28); whilst for other participants the trustworthiness of the quality of the information sourced in chat-rooms was problematic (Quotation 29).
Taboo Subjects in Clinician-led Education Participants identified selfmanagement issues for which education was only available from their peers: either because clinician-led education had not encompassed such topics or because the participants did not feel comfortable about seeking advice about such topics from their clinicians. Such topics included menstruation, sexual function, and recreational drug use (Quotation 30). Whilst many participants had been educated on the impact of alcohol on their glycemic response, participants still turned to peer-led education for methods of dealing with self-management issues related to alcohol use due to their hesitation in discussing such issues with their health team (Quotation 31). Self-management education in the use of recreational or illicit drugs was an area that participants identified as not being adequately addressed in clinician-led education. Participants who had taken recreational or illicit drugs had relied solely on peer-led education. That education was sourced through friends, Internet chat lines, and blogs (Quotation 32).

\section{Diabetes Consumer Organization-led} Learning Many participants supplemented their clinician-led diabetes education by attending forums organized by diabetes support organizations. However, accessibility issues for attendance at these educational forums caused by work or other commitments created problems (Quotation 33). Participants considered that technology could potentiate accessibility to diabetes education, in particular by the ability to view educational sessions online. However, participants perceived that clinicians and diabetes consumer organizations had not optimized their use of such tools (Quotations 34 and 35) 


\section{DISCUSSION}

This research set out to explore issues related to diabetes education that young adults report could be more comprehensively addressed to enhance their autonomy and confidence in diabetes self-management. The findings reveal that young adults with T1D perceive that gaps in diabetes knowledge can eventuate by clinician assumptions about their previous diabetes education; that clinician-led diabetes education tends to be didactic and not emphasize skills for self-directed learning; that there are opportunistic stages of learning; that there are taboo subjects in clinician-led education; that clinicians should further promote education on new technologies; that acknowledgment by clinicians of gaps in the scientific understanding of diabetes would be beneficial, that failure to do so erodes the therapeutic relationship, leads to 'trial and error' regimens and promotes reliance on peerled education; that there are dilemmas inherent in peer-led education, and that diabetes consumer led-education could be more user friendly.

Our finding that knowledge gaps can eventuate suggests that young adults with T1D might benefit from the availability of a comprehensive structured education program, accessible at appropriate intervals throughout the patient journey. Studies evince the effectiveness of a variety of structured programs [40, 42, 49]. A comprehensive education program could either be incorporated into patients' continuing clinician-led education or ancillary to it. The availability of a comprehensive education program in the period before exit from pediatric services or entry into adult services would help to mitigate knowledge gaps created by incorrect clinician assumptions of an adolescent's diabetes knowledge as they transition to autonomous self-management. Access to a comprehensive education program would also benefit those that may have been overwhelmed by their initial diabetes education at diagnosis and enable such persons to address knowledge gaps without having to provide explanation or acknowledgment for their failure to fully comprehend their initial education. Access to a comprehensive education program would also assist to negate knowledge fragmentation due to piecemeal continuing diabetes education. Patient perceptions of fragmented knowledge due to piecemeal continuing diabetes education have been reported elsewhere [49]. Our findings suggest that there has not been adequate promotion by clinicians of available structured education programs such as the DAFNE course, notwithstanding that studies report improved glycemic control and quality of life for patients following such training [50].

Our findings that clinician-led diabetes education tends towards the didactic, and not based on the principles of problem-based learning, suggests that current recommendations on the pedagogy of diabetes education are not being widely implemented for young adults with T1D in Australia [51]. The autonomous capacity of an individual to improve their health literacy is an important component of patient-centered care and should be an integral feature of the curriculum of clinician-led education. Our finding that participants noticed stages of motivation towards undertaking diabetes education is consistent with the stages of behavior change model [52]. This finding supports stagematched promotion of education interventions and proactive recruitment procedures for further diabetes education by clinicians dependent upon the theoretically 
cyclical nature of motivation. Easy access to online, institutionally endorsed educational tools might opportunistically maximize the stage-matched promotion of diabetes education and strategies to assist with selfmanagement and is consistent with positive research findings regarding health promotion tools [52].

That participants had to rely on peer-led education to understand the glycemic response to sexual and lifestyle activities implies that there are taboo topics in clinician-led education that are not being routinely addressed. Changes in the glycemic response to menstruation have been reported and specific discussion of menstrual changes that may impact on glycemia should be routinely incorporated into the diabetes education program of any female with T1D, post menarche [53]. Educational diabetes management considerations should include anticipated glycemic responses to all gender-specific sexual activities. As it is recommended that diabetes education become more individualized, clinicians need to be aware of their patients' lifestyle choices including recreational drug use. It is not adequate that education on the glycemic response to recreational drugs is dependent upon peer-led experience. Young adults should be encouraged to seek clinician education, which should be matched with psychological support for healthier lifestyle choices.

Reports by our participants that many clinicians are 'technophobic' and do not initiate patient education about new technologies to assist with self-management stands in contrast to the reported needs of young adults with T1D that they want to be kept up-to-date with knowledge of the latest technologies [44]. That young Australian adults with T1D need to resort to self-education regarding new technologies has been previously reported [54]. It has been asserted that diabetes education is not adequate when clinician provision is determined by the desire of the patient to have to request or seek out that information [55].

Our results indicate that there may be inherent benefits in clinician acknowledgment and discussion in diabetes education of the imperfect scientific understanding of the physiology of glycemia. Such discussion would prepare young adults with T1D for variable responses to recommended regimens. The imperfect scientific understanding of the glycemic response to a mixed food diet was established by a recent study assessing the role of glycemic load (GL) on insulinemia. GL, the best available predictor, explained less than half the predicted variability on post-prandial insulinemia. The authors concluded: "Factors unknown and potentially more important than GL are yet to be discovered" [56]. Clinician-led warnings might contribute to better selfmanagement practices as they would assist in minimizing patient blame for unexplained glycemic variation; increase patient trust in clinician understanding of diabetes management and provide a basis for why inconsistent advice may be provided by different clinicians in the health care team. The provision of inconsistent and contradictory information by clinicians has been recorded elsewhere [55].

Our results indicate that peer-led education and support is a vital component for improvement of self-management skills for young adults with T1D. Studies suggest that peer involvement in diabetes education leads to improved outcomes [57-59]. Yet most of our participants reported that they had accessed 
peer-education and support themselves without clinicians directing them to those resources. Clinicians should consider an emphasis on assisting patients to establish peer education and support networks.

Gaining insight into the perspectives of young adults with T1D reveals challenges to more effective diabetes education. By addressing these challenges we would then be on the road to more patient-centered systems of care and the benefits for both patients and clinicians that such systems provide, including improved glycemic control [60, 61], greater patient satisfaction [61, 62], higher levels of patient well-being [62, 63], increased patient engagement [61-63], and more provider satisfaction [63].

\section{Study Limitations}

A major limitation of this study was the biased sample because of recruitment by self-selection and through advertisements in diabetes-related support organizations. Eighty percent of the survey sample was female; $84 \%$ had private health insurance, and $78.7 \%$ had tertiary or higher levels of education. These are higher than national averages. As well, $34 \%$ of the sample reported their last glycated hemoglobin A1c (HbA1c) level was $<7 \%(53 \mathrm{mmol} / \mathrm{mol})$, whereas it has been reported that $<20 \%$ of adults with diabetes in Australia maintain a HbA1c level of $<7 \%(53 \mathrm{mmol} / \mathrm{mol}) \quad[13,14]$. Our attrition rate from all services was $2 \%$, whereas attrition rates in Australia have been reported in this age group as high as 50\% $[13,46]$. The demographic and clinical characteristics of our sample indicate a bias towards patients that actively sought out and were more motivated toward further diabetes education. The clinical indicators recorded in our survey were self-reported: results may be subject to recall and reporting bias. Further research is required to determine the perceptions of young adults in a less motivated group. Our research was limited to young adults with T1D: these results may not be generalizable across all age groups of patients with T1D.

\section{CONCLUSION}

This study is one of very few studies that have sought the opinion of young adults with T1D about their experiences of diabetes education. Assisting T1D self-management practices by improving health literacy and, therefore, promoting patient autonomy can be instrumental in improving glycemic control, thereby avoiding diabetes-related disease complications. Our findings indicate that there are opportunities to further develop clinician led-diabetes education, to improve patient outcomes by enhancing autonomous health literacy skills, and to incorporate peer-led education and support with clinician-led education. Our results provide evidence for the potential value of patient engagement in quality improvement and the redesign of health services. This study provides insights into ways that may assist in improving health service delivery and health outcomes through improved diabetes education services for these young adults.

\section{ACKNOWLEDGMENTS}

We thank the young adults that were involved in the interviews and or the survey for their contribution to this research.

This research was conducted under the auspices of a program of research funded by the National Health and Medical Research 
Council (NHMRC) of Australia. The failure of the majority of Australian adults to reach clinically dictated treatment target levels of T1D control is a case study in the program.

All named authors meet the ICMJE criteria for authorship for this manuscript, take responsibility for the integrity of the work as a whole, and have given final approval for the version to be published.

Authors' contributions. Janice Wiley (JW) conducted the study, analyzed the data, contributed to discussions, and wrote, reviewed, and edited the manuscript. Mary Westbrook (MW) analyzed data, contributed to discussions, and reviewed and edited the manuscript. Janet Long (JL) analyzed the data; Jeffrey Braithwaite, Richard Day and Jerry Greenfield contributed to discussions, and reviewed and edited the manuscript. Janice Wiley is the guarantor of this work, had full access to all the data in the study, and takes responsibility for the integrity of the data and the accuracy of the data analysis.

Conflict of interest. Janice Wiley, Mary Westbrook, Janet Long, Richard Day, Jerry Greenfield and Jeffrey Braithwaite declare they have no conflict of interest.

Compliance with ethics. The University of New South Wales granted ethics approval: HREC 10395. All procedures followed were in accordance with the ethical standards of the responsible committee Ion human experimentation (institutional and national) and with the Helsinki Declaration of 1975, as revised in 2000. Informed consent was obtained from all participants in this study.

Open Access. This article is distributed under the terms of the Creative Commons
Attribution Noncommercial License which permits any noncommercial use, distribution, and reproduction in any medium, provided the original author(s) and the source are credited.

\section{REFERENCES}

1. Grant L, Lawton J, Hopkins D, Elliott J, Lucas S, Clark $\mathrm{M}$, et al. Type 1 diabetes structured education: what are the core self-management behaviours? Diabet Med. 2013;30(6):724-30.

2. Gilbertson HR, Brand-Miller JC, Thorburn AW, Evans S, Chondros P, Werther GA. The effect of flexible low glycemic index dietary advice versus measured carbohydrate exchange diets on glycemic control in children with type 1 diabetes. Diabetes Care. 2001;24(7):1137-43.

3. Parillo M, Annuzzi G, Rivellese AA, Bozzetto L, Alessandrini R, Riccardi G, et al. Effects of meals with different glycaemic index on postprandial blood glucose response in patients with Type 1 diabetes treated with continuous subcutaneous insulin infusion. Diabet Med. 2011;28(2):227-9.

4. Marsh K, Barclay A, Colagiuri S, Brand-Miller J. Glycemic index and glycemic load of carbohydrates in the diabetes diet. Curr Diab Rep. 2011;11(2):120-7.

5. MacDonald K, Lowe JM, Barker D, Mensch M, Attia J. Effect of popular takeaway foods on blood glucose levels in type 1 diabetes mellitus patients on intensive insulin therapy. Int $\mathrm{J}$ Clin Pract. 2009;63(2):189-94.

6. Porcellati F, Bolli GB, Fanelli CG. Pharmacokinetics and pharmacodynamics of basal insulins. Diabetes Technol Ther. 2011;13(Suppl 1):S15-24.

7. Heptulla RA, Rodriguez LM, Mason KJ, Haymond MW. Gastric emptying and postprandial glucose excursions in adolescents with type 1 diabetes. Pediatr Diabetes. 2008;9(6):561-6.

8. Silverstein J, Klingensmith G, Copeland K, Plotnick L, Kaufman F, Laffel L, et al. Care of children and adolescents with type 1 diabetes a statement of the American Diabetes Association. Diabetes Care. 2005;28(1):186-212.

9. The Diabetes Control and Complications Trial Research Group. The effect of intensive treatment of diabetes on the development and progression of 
long-term complications in insulin-dependent diabetes mellitus. NEJM. 1993;329(14):977-86.

10. Nathan D, Cleary P, Backlund J, Genuth S, Lachin $J$, Orchard $T$, et al. Intensive diabetes treatment and cardiovascular disease in patients with type 1 diabetes. $\mathrm{N}$ Engl $\mathrm{J}$ Med. $2005 ; 353(25): 2643-53$.

11. Genuth S. Insights from the diabetes control and complications trial/epidemiology of diabetes interventions and complications study on the use of intensive glycemic treatment to reduce the risk of complications of type 1 diabetes. Endocr Pract. 2006;12:34-41.

12. Martin CL, Albers J, Herman WH, Cleary P, Waberski B, Greene DA, et al. Neuropathy among the diabetes control and complications trial cohort 8 years after trial completion. Diabetes Care. 2006;29(2):340-4.

13. McIntyre DH. DAFNE (Dose Adjustment for Normal Eating): structured education in insulin replacement therapy for type 1 diabetes. Med J Aust. 2006;184(7):317.

14. Bryant W, Greenfield JR, Chisholm DJ, Campbell LV. Diabetes guidelines: easier to preach than to practise? Med J Aust. 2006;185(6):305-9.

15. Mortensen HB, Hougaard P. Comparison of metabolic control in a cross-sectional study of 2,873 children and adolescents with IDDM from 18 countries. Diabetes Care. 1997;20(5): 714-20.

16. Laing SP, Swerdlow AJ, Slater SD, Burden AC, Morris A, Waugh NR, et al. Mortality from heart disease in a cohort of 23,000 patients with insulin-treated diabetes. Diabetologia. 2003;46(6):760-5.

17. Clement S. Diabetes self-management education. Diabetes Care. 1995;18(8):1204-14.

18. Heller SR. Structured education in type 1 diabetes. Br J Diabetes Vasc Dis. 2009;9(6):269-72.

19. Diabetes UK. Improving supported selfmanagement for people with diabetes. 2009. http://www.diabetes.org.uk/Documents/Reports/ Supported_self-management.pdf. Accessed Oct 7, 2013.

20. Diabetes UK. Diabetes in the UK: key statistics in diabetes; 2012. https://www.diabetes.org.uk/ About_us/What-we-say/Statistics/Diabetes-in-theUK-2012/. Accessed Oct 7, 2013.

21. American Diabetes Association. Standards of medical care in diabetes-2012. Diabetes Care. 2012;35(Supplement 1):S11-63.
22. National Institute for Clinicial Excellence. Type 1 diabetes: diagnosis and management of type 1 diabetes in children, young people and adults. London: National Institute for Clinical Excellence; 2004. http://www.nice.org.uk/nicemedia/pdf/CG015child renfullguideline.pdf. Accessed Oct 7, 2013.

23. Craig ME, Twigg SM, Donaghue KC, Cheung NW, Cameron FJ, Conn J, et al. National evidence-based clinical care guidelines for type 1 diabetes for children, adolescents and adults. Canberra: Australian Government Department of Health and Ageing; 2011. http://www.nhmrc.gov.au/_files_ nhmrc/publications/attachments/ext004_type 1 diabetes_children_adolescents_adults.pdf. Accessed Oct 7, 2013.

24. The Audit Commission. Testing times: a review of diabetes services in England and Wales. London: Department of Health; 2000. http://archive.auditcommission.gov.uk/auditcommission/sitecollection documents/AuditCommissionReports/NationalStu dies/nrdiabet.pdf. Accessed Oct 7, 2013.

25. Funnell MM, Brown TL, Childs BP, Haas LB, Hosey GM, Jensen B, et al. National standards for diabetes self-management education. Diabetes Care. 2009; 32(Supplement 1):S87-94.

26. Kawaguchi T. Certified diabetes expert nurse and nurse educators in Japan. Diabetes Res Clin Pract. 2007;77(3, Supplement):S205-7.

27. Yu N-C, Su H-Y, Tsai S-T, Lin BJ, Shiu R-S, Hsieh Y-C, et al. ABC control of diabetes: survey data from National Diabetes Health Promotion Centers in Taiwan. Diabetes Res Clin Pract. 2009;84(2): 194-200.

28. Haas L, Maryniuk M, Beck J, Cox CE, Duker P, Edwards L, et al. National standards for diabetes self-management education and support. Diabetes Care. 2013;36(Supplement 1):S100-8.

29. Aslani P, Krass I. Adherence: a review of education, research, practice and policy in Australia. Pharm Pract (Internet). 2009;7(1):1-10.

30. Murphy H, Rayman G, Skinner T. Psychoeducational interventions for children and young people with Type 1 diabetes. Diabet Med. 2006;23(9):935-43.

31. Assal JP, Muhlhauser I, Pernet A, Gfeller R, Jorgens $\mathrm{V}$, Berger M. Patient education as the basis for diabetes care in clinical practice and research. Diabetologia. 1985;28(8):602-13.

32. Anderson BJ, Wolpert HA. A developmental perspective on the challenges of diabetes education and care during the young adult period. Patient Educ Couns. 2004;53(3):347-52. 
33. Deci EL, Ryan RM. The "what" and "why" of goal pursuits: human needs and the self-determination of behavior. Psychol Inq. 2000;11(4): 227-68.

34. Williams GC, McGregor HA, Zeldman A, Freedman ZR, Deci EL. Testing a self-determination theory process model for promoting glycemic control through diabetes self-management. Health Psychol. 2004;23(1):58-66.

35. Bandura A. Human agency in social cognitive theory. Am Psychol. 1989;44(9):1175.

36. Bandura A. Social learning theory. New York: General Learning Press; 1977.

37. Group DS. Training in flexible, intensive insulin management to enable dietary freedom in people with type 1 diabetes: dose adjustment for normal eating (DAFNE) randomised controlled trial. BMJ. 2002;325:746-9.

38. Dinneen SF, O'Hara MC, Byrne M, Newell J, Daly L, O'Shea D, et al. The Irish DAFNE study protocol: a cluster randomised trial of group versus individual follow-up after structured education for type 1 diabetes. Trials. 2009;10(1):88.

39. Mühlhauser I, Bruckner I, Berger M, Cheţa D, Jörgens V, Ionescu-Tîrgoviş̧te C, et al. Evaluation of an intensified insulin treatment and teaching programme as routine management of type 1 (insulin-dependent) diabetes. Diabetologia. 1987;30(9):681-90.

40. Rankin D, Cooke D, Clark M, Heller S, Elliott J, Lawton J. How and why do patients with Type 1 diabetes sustain their use of flexible intensive insulin therapy? A qualitative longitudinal investigation of patients' self-management practices following attendance at a Dose Adjustment for Normal Eating (DAFNE) course. Diabet Med. 2011;28(5):532-8.

41. Association AD. Standards of medical care in diabetes2013. Diabetes Care. 2013;36(Supplement 1): S11-66.

42. Rankin D, Cooke DD, Elliott J, Heller SR, Lawton J, Group UNDS. Supporting self-management after attending a structured education programme: a qualitative longitudinal investigation of type 1 diabetes patients' experiences and views. BMC Public Health. 2012;12:652.

43. Koch S. Improving quality of life through eHealththe patient perspective. Stud Health Technol Inform. 2012;180:25-9.

44. Eigenmann C, Colagiuri R. Outcomes and indicators for diabetes education-a national consensus position; 2007. http://www.ndss.com. $\mathrm{au} /$ PageFiles/763/Outcomes\%20and\%20Indicators\% 20report.pdf. Accessed May 8, 2013.

45. Peters A, Laffel L, American Diabetes Association Transitions Working Group. Diabetes care for emerging adults: recommendations for transition from pediatric to adult diabetes care systems: a position statement of the American Diabetes Association, with representation by the American College of Osteopathic Family Physicians, the American Academy of Pediatrics, the American Association of Clinical Endocrinologists, the American Osteopathic Association, the Centers for Disease Control and Prevention, Children with Diabetes, The Endocrine Society, the International Society for Pediatric and Adolescent Diabetes, Juvenile Diabetes Research Foundation International, the National Diabetes Education Program, and the Pediatric Endocrine Society (formerly Lawson Wilkins Pediatric Endocrine Society). Diabetes Care. 2011;34(11):2477-85.

46. Perry L, Steinbeck KS, Dunbabin JS, Lowe JM. Lost in transition? Access to and uptake of adult health services and outcomes for young people with type 1 diabetes in regional New South Wales. Med J Aust. 2010;193(8):444-9.

47. Morgan DL, Krueger RA. When to use focus groups and why. In: Morgan DL, editor. Successful focus groups: advancing the state of the art. Newbury Park: Sage; 1993. p. 3-19.

48. Thomas DR. A general inductive approach for analyzing qualitative evaluation data. Am J Eval. 2006;27(2):237-46.

49. Jordan LVM, Robertson M, Grant L, Peters REL, Cameron JT, Chisholm S, et al. Tayside insulin management course: an effective education programme. J Clin Pract. 2013;67(5):462-8.

50. Hopkins D, Lawrence I, Mansell P, Thompson G, Amiel S, Campbell M, et al. Improved biomedical and psychological outcomes 1 year after structured education in flexible insulin therapy for people with type 1 diabetes: the U.K. DAFNE experience. Diabetes Care. 2012;35(8):1638-42.

51. American Association of Diabetes Educators. AADE position statement: individualization of diabetes self-management education. Diabetes Educ. 2007;33(1):45-9.

52. Prochaska JO, Velicer WF. The transtheoretical model of health behavior change. Am J Health Promot. 1997;12(1):38-48.

53. Cawood EH, Bancroft J, Steel JM. Perimenstrual symptoms in women with diabetes mellitus and the relationship to diabetic control [Erratum appears in 
Diabet Med 1993 Oct; 10(8):685]. Diabet Med. 1993;10(5):444-8.

54. Perry L, Lowe JM, Steinbeck KS, Dunbabin JS. Services doing the best they can: service experiences of young adults with type 1 diabetes mellitus in rural Australia. J Clin Nurs. 2012;21(13-14):1955-63.

55. Rankin D, Heller S, Lawton J. Understanding information and education gaps among people with type 1 diabetes: a qualitative investigation. Patient Educ Couns. 2011;83(1):87-91.

56. Bao J, Atkinson F, Petocz P, Willett WC, BrandMiller JC. Prediction of postprandial glycemia and insulinemia in lean, young, healthy adults: glycemic load compared with carbohydrate content alone. Am J Clin Nutr. 2011;93(5):984-96.

57. Markowitz JT, Laffel LMB. Transitions in care: support group for young adults with Type 1 diabetes. Diabet Med. 2012;29(4):522-5.

58. Dale JR, Williams SM, Bowyer V. What is the effect of peer support on diabetes outcomes in adults? A systematic review. Diabet Med. 2012;29(11): 1361-77.
59. Selvais PL, Amoussou-Guenou KD, Hermans MP. Belonging to a diabetes patients' association is predictive of better metabolic control. Diabetes Metab. 2008;34(3):279-82.

60. Attale C, Lemogne C, Sola-Gazagnes A, Guedeney $\mathrm{N}$, Slama G, Horvath AO, et al. Therapeutic alliance and glycaemic control in type 1 diabetes: a pilot study. Diabetes Metab. 2010;36(6 Pt 1):499-502.

61. Cvengros JA, Christensen AJ, Cunningham C, Hillis SL, Kaboli PJ. Patient preference for and reports of provider behavior: impact of symmetry on patient outcomes. Health Psychol. 2009;28(6):660-7.

62. Kinmonth AL, Woodcock A, Griffin S, Spiegal N, Campbell MJ. Randomised controlled trial of patient centred care of diabetes in general practice: impact on current wellbeing and future disease risk. The Diabetes Care From Diagnosis Research Team. BMJ. 1998;317(7167):1202-8.

63. Bauman A, Fardy H, Harris P. Getting it right: why bother with patient-centred care? Med J Aust. 2003;179(5):253-6. 